Aim of the study. Cancer is usually associated with impaired nutritional status, which is one of the factors contributing to the deterioration of the results of surgery, chemotherapy, or radiotherapy. The aim of this study was the assessment of the nutritional status of patients with CRC qualified to chemotherapy.

Material and methods: Seventy-five persons aged 40-86 years with colorectal cancer were examined.

To evaluate the nutritional status NRS 2002, SGA, SCRINIO Working Group classification, VAS scale for appetite, and FAACT questionnaire were used. The health status of patients was evaluated based on the Karnofsky Performance Scale. Anthropometric measurements were made.

Results: The results indicate that $75 \%$ of patients present pre-cachexia status based on SCRINIO Working Group classification. According to both NRS2002 and SGA, $73.3 \%$ of patients were moderately malnourished and $2.7 \%$ were severely malnourished. $37.0 \%$ of patients had moderate appetite and $6.0 \%(n=5)$ had poor appetite. The Karnofsky score indicates the state of normal activity, and minor signs and symptoms of the disease among most of the patients. A statistically significant positive correlation was found between the VAS and the Karnofsky score $(R=0,4 ; p<0.05)$. The FACCT average score (78.5) indicates a reduction in the quality of life of the patients in all aspects of functioning. Conclusions: Evaluation of the baseline nutritional status of patients with CRC should be a part of routine clinical practice. Because of the high incidence of confirmed pre-cachexia, this group of patients also requires early adequate nutrition intervention.

Key words: colorectal cancer, chemotherapy, nutritional status, appetite, quality of life, malnutrition.

Contemp Oncol (Pozn) 2017; 21 (2): 157-161 DOI: https://doi.org/10.5114/wo.2017.68625

\section{Nutritional status assessment in colorectal cancer patients qualified to systemic treatment}

\author{
Monika Ziętarska ${ }^{1}$, Joanna Krawczyk-Lipiec ${ }^{2}$, Leszek Kraj², Renata Zaucha ${ }^{3}$, \\ Sylwia Małgorzewicz ${ }^{1}$
}

${ }^{1}$ Department of Clinical Nutrition, Medical University of Gdansk, Poland

2Department of Haematology, Oncology, and Internal Medicine, Medical University of Warsaw, Poland

${ }^{3}$ Department of Oncology and Radiotherapy, Medical University of Gdansk, Poland

\section{Introduction}

The presence of a malignant tumour is a specific example of the deep interference of the disease itself, and anticancer therapy, in metabolism and homoeostasis. Therefore, a common manifestation of the development of a neoplastic disease is a progressive loss of body weight and varying degrees of malnutrition, which constitutes a important problem in oncology.

According to available data, the percentage of patients with observed abnormal nutritional status is significant - it is in fact between about 40 to as much as over 80 per cent, depending on, e.g., the location of the tumour and the neoplasm stage [1-5]. It is worth mentioning that cachexia and cancer anorexia-cachexia syndrome (CACS) are metabolism and energy disturbances specific for neoplastic diseases. In accordance with the international consensus they are multifactorial clinical syndromes with extremely complex etiopathogenesis and characterized by a progressive loss of lean body mass, functional disorders, and a varied degree of impaired appetite [6].

It is an important fact that these deficiencies constitute a continuum of a clinical form of pre-cachexia, cachexia, and refractory cachexia. According to one of the existing classifications - the SCRINIO Working Group Classification - there are four degrees/classes of severity, from asymptomatic pre-cachexia (Class I - weight loss $<10 \%$ without noticeable appetite impairment) to full-blown cachexia (Class IV - weight loss > 10\% of accompanying fatigability, anorexia, or early feeling of satiety) [7, 8].

Malignant tumours are in fact a heterogeneous group of diseases; therefore, metabolic abnormalities and nutritional problems may be different depending on the type, location, and stage of tumour.

In the available literature there is relatively little data on the nutritional status and nature of nutritional problems in patients with colorectal cancer (CRC) qualified for chemotherapy / systemic therapy. It seems interesting to determine the percentage of people meeting the criteria of the early stages of cachexia (pre-cachexia), as well as possible relationships between dietary aspects and the quality of life, and the overall performance state in this group of people.

\section{Aim of the study}

The aim of this study is a prospective and comprehensive assessment of nutritional status including the assessment of appetite, quality of life, and overall performance state of patients with CRC at II-IV clinical stage, who are qualified to begin chemotherapy. It seems that the knowledge of these issues can be applied into clinical practice. 


\section{Material and methods}

The study received approval of the Ethics Committee of the Medical University of Gdansk. Informed consent was obtained from all individual participants included in the study. Seventy-five persons aged 40-86 years $(65.7 \pm 10.2)$, 43 males $(M)$ and 32 females $(F)$, were examined. The study was conducted in the Department of Oncology and Radiotherapy in the Medical University of Gdansk. Patients were treated by an oncologist, and nutritional assessment was performed by an internal medicine physician.

All patients had histopathologically confirmed diagnosis of colorectal cancer. The locations of the tumours were as follows:

- caecum 3 persons (4.0\%),

- ascending colon 44 persons (58.6\%),

- sigmoid colon 12 persons (16.0\%),

- rectum 16 persons (21.3\%).

Based on the TNM classification, 17 persons had fourth stage (22.6\%), 40 persons (53.3\%) had third stage, and 18 persons $(24.0 \%)$ had the second stage. Metastases to lymph nodes were diagnosed in 28 persons. Distant metastases: lung, ovary, liver, bladder, kidney, and adrenal glands were found in 21 persons. Five patients (6.7\%) were in the second clinical stage, 51 patients (68\%) - in the third stage, and four patients (5.3\%) - in the fourth stage.

Patients were qualified to receive treatment with chemotherapy. $41.0 \%$ of patients in the study were qualified to receive FOLFOX regimen, and the remnaining patients were qualified to the following regimens FOLFIRI, LF, CLF, and XELOX.

The following methods were used in the study:

- body mass measurement with the use of the Tanita BC 420 scale;

- body mass index calculation (BMI) based on the following formula:

- BMI = body weight/height ${ }^{2}\left(\mathrm{~kg} / \mathrm{m}^{2}\right)$.

BMI classification was adopted:

- $<18.5$ - underweight,

- 18.5-24.9 - normal body weight,

- 25.0-29.9- overweight,

- $<30.0$ - obesity.

Also, the following scores were used:

- Nutritional Risk Screening (NRS 2002), Subjective Global Assessment (SGA), Visual Analog Scale for Appetite (VAS), Functional Assessment of Anorexia/Cachexia Therapy (FACCT), and the Karnofsky score to quantify patients' performance status.

- NRS 2002 - a given score is given to a patient based on unintentional weight loss, BMI, consumption quantity, clinical condition, and age. Gaining three or more points means a risk of malnutrition.

- SGA - based on this method, consisting of an interview, unintentional weight loss, clinical status, and physical examination, patients were qualified to the following groups: well-nourished (7 or 6 points), moderately malnourished (5, 4, or 3 points), and severely malnourished (1 or 2 points).
- VAS, FACCT forms were completed by patients based on their feelings regarding appetite and well-being during the previous seven days.

- VAS for appetite is represented by a 100-mm line where $0 \mathrm{~mm}$ means "I had no appetite at all" and $100 \mathrm{~mm}$ means "My appetite was very good". The VAS score is obtained by measuring the distance (in millimetres) from 0 point "I had no appetite at all" to the point selected by a patient.

- The lower the score - the worse the appetite. It was assumed that below $70 \mathrm{~mm}$ the appetite is moderately reduced, and below $50 \mathrm{~mm}$ it is severely reduced (weak).

- FAACT is a measure of the quality of life and it is completed by a patient; it has a total of 42 questions. Patients mark 0 (none) to 4 (very much) for each question. This tool consists of five subscales: functional well-being (7 items), physical well-being (7 items), social/family well-being (7 items), emotional well-being ( 6 items), and other aspects, including appetite (13 items).

- The maximum score is 168 . The lower the score, the lower the overall quality of life.

- The Karnofsky score allows us to quantify the overall state and quality of life of a patient with neoplastic disease, who qualifies to receive chemotherapy. The score has a range from 0 to 100, where 100 represents the ideal state and 0 represents death.

- Pre-cachexia was diagnosed on the basis of SCRINIO Working Group Classification, i.e.

- unintentional weight loss in the past 6 months $<10 \%$, - no anorexia.

The cachexia was diagnosed when the weight loss was $>10 \%$ in the past 6 months.

\section{Statistical analysis}

Results are expressed as percentages (for categorical variables), mean and standard deviation, or median and interquartile range, as appropriate. The assumption of normality was verified with the Kolmogorov-Smirnov test. A $p$-value $<0.05$ was considered to be statistically significant. To assess correlations among the evaluated variables, Pearson's correlation coefficient $(r)$ was used. Statistical processing of the results was performed with the use of the statistical software STATISTICA PL $\vee 12.0$ (Statsoft, Krakow, Poland).

\section{Results:}

In the study group the mean unintentional weight loss during the previous six months was $6.7 \mathrm{~kg}$ (median $6 \mathrm{~kg}$ ) and ranged from $1.1 \mathrm{~kg}$ to $15.0 \mathrm{~kg}$. The mean BMI was within normal limits and was 24.5.

The percentage of underweight, overweight, and obese patients is shown in Fig. 1.

The positive correlation between age and $B M I(R=0.3$, $p<0.05)$ and also between BMI and SGA $(\mathrm{R}=0.3, p<0.05)$ and NRS $2002(R=-0.4 ; p<0.05)$ were observed.

The results of NRS 2002 assessment: 57 persons (76\%) in the study group received three or more points, which indicates the risk of malnutrition or malnutrition and indicates the need for nutritional intervention. SGA: similarly, 


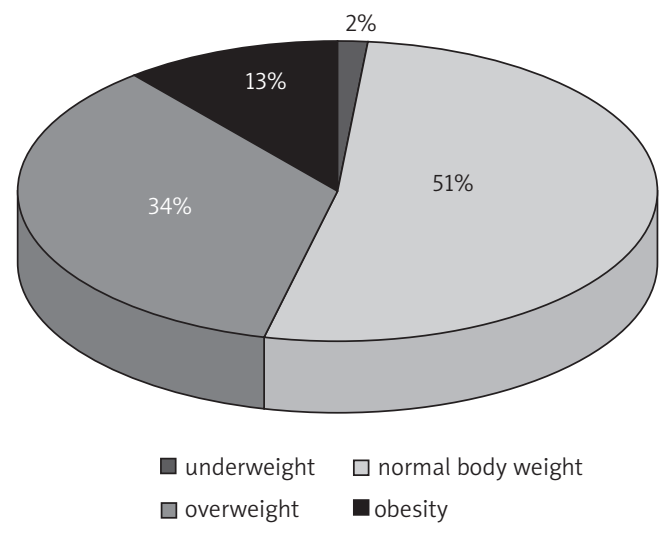

Fig. 1. The percentage of patients in each BMI category

55 persons (73.3\%) were classified as presenting a moderate malnutrition group (received 5, 4, or 3 points) and two persons $(2.7 \%)$ - a group of significantly malnourished persons (received 2 points).

The results of appetite evaluation made with the use of VAS are shown in Fig. 2. 37.0\% $(n=28)$ of patients had moderate appetite and 6.0\% $(n=5)$ of patients had poor appetite.

The Karnofsky score results (Table 1) indicate the state of normal activity, with minor signs and symptoms of the disease among the majority of patients. A statistically significant positive correlation between VAS and the Karnofsky score can be seen $(R=0.4 ; p<0.05)$.

The FACCT average score ( 78.5 points) indicates a reduction in the quality of life of the patients in all aspects of functioning.

Based on the SCRINIO Working Group Classification 56 patients (75\%) had precachexia (average weight loss in this group was $8 \%$ ).

Cachexia was diagnosed in 19 persons (25\% of patients).

\section{Discussion}

The results confirm the existing problem of disturbance in the nutritional status of patients with CRC. Although severe eating disorders (anorexia) were not confirmed in the majority of patients and the median/average BMI was within the range of reference values, the average weight loss was greater than $5 \%$ in the preceding 6 months, which should be considered clinically relevant.

Other studies also confirm the occurrence of abnormal nutritional and weight loss in patients with CRC, but the data on this issue in the literature are rather scarce. For example, in one study weight loss was observed in more than half of the patients before any surgical treatment, and one in five patients was malnourished [9]. On the other hand, other authors observed a weight loss of over $5 \%$ in $23.5 \%$ of patients and hypoalbuminaemia in more than $35 \%$ patients [10].

Based on the results of this study, it was concluded that severe malnutrition or actual cancer cachexia do not often occur in patients with CRC, but the first stage of it - preca-

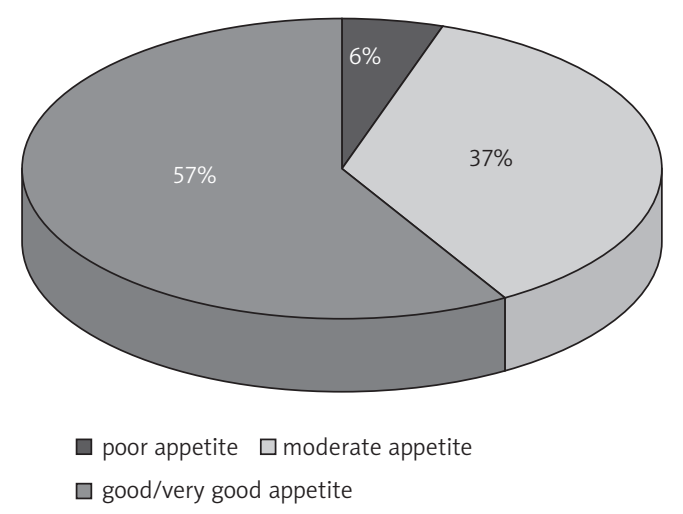

Fig. 2. The percentage of patients with reduced appetite

Table 1. Characteristics of the patients

\begin{tabular}{|c|c|}
\hline Parameters & $\begin{array}{l}\text { Study group } \\
\quad(n=75)\end{array}$ \\
\hline $\mathrm{BMI}\left(\mathrm{kg} / \mathrm{m}^{2}\right)$ & $\begin{array}{c}25.1 \pm 3.9 \\
\text { range } 17.1-37.1 \\
\text { median } 24.5\end{array}$ \\
\hline Body fat (\%) & $\begin{array}{c}26.7 \pm 9.7 \\
\text { Range } 9.9-44.4 \\
\text { Median } 26.0\end{array}$ \\
\hline Body fat (kg) & $\begin{array}{c}19.2 \pm 9.3 \\
\text { Range } 4.3-44.0 \\
\text { Median } 18.0\end{array}$ \\
\hline Fat Free Mass (kg) & $\begin{array}{c}50.2 \pm 9.2 \\
\text { Range } 39.6-75.8 \\
\text { Median } 47.1\end{array}$ \\
\hline Muscle Mass (kg) & $\begin{array}{c}47.8 \pm 8.7 \\
\text { Range } 29.0-72.1 \\
\text { Median } 45.0\end{array}$ \\
\hline Total Body Water (kg) & $\begin{array}{c}34.7 \pm 6.6 \\
\text { Range } 20.0-51.2 \\
\text { Median } 33.1\end{array}$ \\
\hline Total Body Water (\%) & $\begin{array}{c}50.7 \pm 6.6 \\
\text { Range } 39.3-65.6 \\
\text { Median } 50.1\end{array}$ \\
\hline NRS 2002 (points) & $\begin{array}{c}2.9 \pm 0.6 \\
\text { Range } 2.9-5.0 \\
\text { Median } 3.0\end{array}$ \\
\hline $\begin{array}{l}\text { SGA } \\
\text { (points) }\end{array}$ & $\begin{array}{c}4.8 \pm 0.9 \\
\text { Range } 2.0-6.0 \\
\text { Median } 5.0\end{array}$ \\
\hline VAS $(\mathrm{cm})$ & $\begin{array}{c}6.8 \pm 2.3 \\
\text { Range } 1.0-10.0 \\
\text { Median } 7.0\end{array}$ \\
\hline KARNOFSKY SCORE (\%) & $\begin{array}{c}90.5 \pm 7.7 \\
\text { Range } 60.0-100.0 \\
\text { Median } 90.0\end{array}$ \\
\hline FACCT (points) & $\begin{array}{c}76.3 \pm 15.5 \\
\text { Range } 35-114 \\
\text { Median } 78.5\end{array}$ \\
\hline
\end{tabular}

Data presented as mean $\pm S D$, range, and median 
chexia - was observed in a significant number of patients. Based on SCRINIO Working Group Classification criteria, precachexia was found in almost 3/4 of the patients.

It is an important observation that the first stage of cachexia is reversible by appropriate feeding behaviour (as opposed to the symptoms of cachexia, which by definition is irreversible using only nutritional support). Thus, dietary intervention initiated in time gives the most clinical benefit to the patient, which can be significant.

The negative metabolic and nutritional effects of a neoplastic disease have a close relationship with poor quality of life and overall performance state, limiting the possibility of a causal treatment, reduction of its efficacy and tolerance, and worsened prognosis. Neoplastic cachexia is a powerful independent adverse prognostic factor.

Many studies have confirmed these relationships as well as the positive impact of appropriate nutrition intervention, which is preceded by a comprehensive assessment of nutritional status.

For example, it was observed that patients with gastrointestinal neoplasms experienced worse results of surgical treatment in the case of poor nutritional status as well as delayed and inadequate nutritional support after surgery [11]. In contrast, other researchers found that the presence of neoplastic cachexia is associated with worse function of lungs, shorter overall survival (OS), and a lower overall performance state in patients with pancreatic cancer. Moreover, the weight loss of $5-10 \%$ correlates with reduced possibility for tumour resection, while a low BMI and low preoperative serum albumin (one of the malnutrition markers) correlates with prolonged hospitalisation of patients with resectable tumours [3, 12, 13].

In the group of patients with ovarian cancer an opposite correlation between preoperative serum albumin and OS is confirmed; at albumin level $<25 \mathrm{~g} / \mathrm{l}$ the average survival was 4.8 months, and at a level of $>35 \mathrm{~g} / \mathrm{l}-43.2$ months [14]. Another study has confirmed that patients with moderate or severe malnutrition have lower rates of five-year OS than patients without signs of malnutrition or mild malnutrition (respectively: $45.3 \%$ vs. 64\%). Similarly, the median progression-free survival (PFS) is lower in this group (15 vs. 28 months) [15].

It is also very important to pay attention to nutritional aspects in patients undergoing chemotherapy or combined chemoradiotherapy. Still, the very important role of striving to improve or maintain proper nutritional status before starting an aggressive therapy must be stressed. It has been stated that malnutrition and hypoalbuminaemia significantly increases the toxicity of chemotherapy/ chemoradiotherapy. In contrast, an early assessment of nutrition and implementation of nutritional support, if necessary, can bring significant clinical benefits [7, 16, 17].

The above-listed concerns confirm the enormous impact of comprehensive nutritional care as integrally connected with a causal therapy and/or symptomatic treatment for cancer patients. As already mentioned, nutritional intervention should begin with a nutritional status assessment, information on current nutritional problems, and a specific treatment employed.

In a large retrospective analysis involving more than 40,000 patients with CRC, postoperative mortality was significantly higher in patients with hypoalbuminaemia, weight loss, and low BMI $\left(<18.5 \mathrm{~kg} / \mathrm{m}^{2}\right)$; hypoalbuminaemia $(<3.5 \mathrm{~g} / \mathrm{dl})$ was a powerful factor, which correlated with longer duration of hospitalisation and an increase in the number of complications. Therefore, malnutrition in the preoperative evaluation is associated with increased postoperative morbidity, mortality, and prolonged hospitalisation in patients with CRC [18].

Negative clinical implications of suboptimal nutritional status not only concern patients who are treated surgically, but in principle every method of anticancer therapy both local and systemic.

Regarding systemic treatment, especially chemotherapy, it has been confirmed that it has significantly increased toxicity and reduced efficacy in malnourished patients.

A strong correlation between nutritional status indicators such as body weight, BMI and serum albumin, and overall survival (OS) has been reported in patients with unresectable or relapsed CRC, and who were given chemotherapy [19]. Similarly, the loss of muscle mass (lean body mass) of $>9 \%$ during chemotherapy has been associated with lower rates of survival in patients with metastatic CRC [20]. Therefore, poor nutritional status before and during chemotherapy proves to be an independent prognostic factor $[19,20]$.

Worse nutritional status also correlates with worse quality of life and overall performance status. These relationships have been confirmed in this study by indicating the existence of a correlation between BMI and FACCT (Functional Assessment of Anorexia/Cachexia Therapy) questionnaire score as well as between appetite and overall performance status (according to the Karnofsky score).

In the literature, we also found references to these issues by stating the relationship between weight loss, the development of cachexia, and the poor overall performance status and quality of life in patients with CRC [21, 22]. By contrast, patients who are better nourished have significantly better quality of life and functioning abilities [21].

The positive significance of individual nutritional counselling, special nutritional education, and implementation of nutritional support in patients with CRC is emphasised in the literature. Their beneficial effect on the improvement of appetite, increased intake of nutrients, reduction of weight loss, reduction in morbidity associated with cancer treatment, and improved prognosis, including longterm prognosis, has been confirmed [22-26].

In conclusions, the evaluation of baseline nutritional status of patients with CRC should be a part of routine clinical practice. Because of the high incidence of confirmed precachexia, this group of patients also requires early adequate nutrition intervention. 
This study was funded by NUTRICIA Foundation (grant no. $R G$ 6/2013).

The study received approval of the Ethics Committee of the Medical University of Gdansk (NKBBN/216/2015).

The authors declare no conflict of interest.

\section{References}

1. Lopes JP, de Castro Cardoso Pereira PM, dos Reis Baltazar Vicente AF, Bernardo A, de Mesquita MF. Nutritional status assessment in colorectal cancer patients. Nutr Hosp 2013; 28: 412-8.

2. Krawczyk J, Korta T. Niedożywienie jako problem kliniczny u osób z rozpoznaną chorobą nowotworową leczonych systemowo. Postępy Żywienia Klinicznego 2010; (2): 7-12.

3. Fechtner K, Krakowski-Roosen H, Büchler MW, Friess H, Martignoni ME. Pancreatic cancer related cachexia: influence on metabolism and correlation to weight loss and pulmonary function. BMC Cancer 2009; 9: 255.

4. Bozzetti F; SCRINIO Working Group. Screening the nutritional status in oncology: a preliminary report on 1,000 outpatients. Support Care Cancer 2009; 17: 279-4.

5. Marín Caro MM, Gómez Candela C, Castillo Rabaneda R, et al. Nutritional risk evaluation and establishment of nutritional support in oncology patients according to the protocol of the Spanish Nutrition and Cancer Group. Nutr Hosp 2008; 23: 458-8.

6. Fearon K, Strasser F, Anker SD, et al. Definition and classification of cancer cachexia: an international consensus. Lancet Oncol 2011; 12: 489-5.

7. Capuano G, Gentile PC, Bianciardi F, Tosti M, Palladino A, Di Palma M. Prevalence and influence of malnutrition on quality of life and performance status in patients with locally advanced head and neck cancer before treatment. Support Care Cancer 2010; 18: 433-7.

8. Bozzetti F, Mariani L. Defining and classifying cancer cachexia: a proposal by the SCRINIO Working Group. JPEN I Parenter Enteral Nutr 2009; 33: 361-7.

9. Burden ST, Hill J, Shaffer JL, et al. Nutritional status of preoperative colorectal cancer patients. J Hum Nutr Diet 2010; 23: 402-7.

10. Pan YP, Chang PH, Fan CW, et al. Relationship between pre-treatment nutritional status, serum glutamine, arginine levels and clin icopathological features in Taiwan colorectal cancer patients. Asia Pac J Clin Nutr 2015; 24: 598-604.

11. Garth AK, Newsome CM, Simmance N, Crowe TC. Nutritiona status, nutrition practices and post-operative complications in patients with gastrointestinal cancer. J Hum Nutr Diet 2010; 23: 393-401.

12. Bachmann J, Heiligensetzer M, Krakowski-Roosen H, Büchler MW, Friess H, Martignoni ME. Cachexia worsens prognosis in patients with resectable pancreatic cancer. J Gastrointest Surg 2008; 12: 1193-201.

13. Hendifar A, Osipov A, Khanuja J, Nissen N, Naziri J, Yang W, Li Q Tuli R. Influence of body mass index and albumin on perioperative morbidity and clinical outcomes in resected pancreatic adenocarcinoma. PLoS One 2016; 11: e0152172.

14. Asher V, Lee J, Bali A. Preoperative serum albumin is an independent prognostic predictor of survival in ovarian cancer. Med Oncol 2011; 7: 2005-9.

15. Yim GW, Eoh KJ, Kim SW, et al. Malnutrition identified by the nutritional risk index and poor prognosis in advanced epithelial ovarian carcinoma. Nutr Cancer 2016; 4: 1-8.

16. Arrieta O, Michel Ortega RM, Villanueva-Rodríguez G, et al. Association of nutritional status and serum albumin levels with development of toxicity in patients with advanced non-small cell lung cancer treated with paclitaxel-cisplatin chemotherapy: a prospective study. BMC Cancer. 2010; 21:10-50.

17. Paccagnella A, Morello M, Da Mosto MC, et al. Early nutritional intervention improves treatment tolerance and outcomes in head and neck cancer patients undergoing concurrent chemoradiotherapy. Support Care Cancer 2009; 30.
18. Hu WH, Cajas-Monson LC, Eisenstein S, et al. Preoperative malnutrition assessments as predictors of postoperative mortality and morbidity in colorectal cancer: an analysis of ACS-NSQIP. Nutr 2015; 14: 91.

19. Ihara K, Yamaguchi S, Shida Y, et al. Poor nutritional status before and during chemotherapy leads to worse prognosis in unresectable advanced or recurrent colorectal cancer. Int Surg 2015; 17: 67-71.

20. Blauwhoff-Buskermolen S, Versteeg KS, de van der Schueren MA, et al. Loss of muscle mass during chemotherapy is predictive for poor survival of patients with metastatic colorectal cancer. J Clin Oncol 2016; 22: 1339-44.

21. Thoresen L, Frykholm G, Lydersen S, et al. The association of nutritional assessment criteria with health-related quality of life in patients with advanced colorectal carcinoma. Eur J Cancer Care (Engl) 2012; 21: 505-16.

22. Gupta D, Lis CG, Granick J, et al. Malnutrition was associated with poor quality of life in colorectal cancer: a retrospective analysis. J Clin Epidemiol 2006; 59: 704-9.

23. Dintinjana RD, Guina T, Krznarić Z, Radić M, Dintinjana M. Effects of nutritional support in patients with colorectal cancer during chemotherapy. Coll Antropol 2008; 32: 737-40.

24. Dobrila-Dintinjana R, Trivanovic D, Zelić M, et al. Nutritional support in patients with colorectal cancer during chemotherapy: does it work? Hepatogastroenterology 2013; 60: 475-80.

25. Park KO, Choi-Kwon S. Effects of individualized nutritional education programs on the level of nutrient intake and nutritional status of colorectal cancer patients undergoing palliative chemotherapy J Korean Acad Nurs 2012; 42: 799-809.

26. Ravasco P, Monteiro-Grillo I, Camilo M. Individualized nutrition intervention is of major benefit to colorectal cancer patients: longterm follow-up of a randomized controlled trial of nutritional therapy. Am J Clin Nutr 2012; 96: 1346-53.

\section{Address for correspondence}

\section{Sylwia Małgorzewicz}

Department of Clinical Nutrition

Medical University of Gdańsk

Debinki 7

80-210 Gdansk, Poland

tel. $+48 / 583492724$

$\mathrm{fax}+48 / 583492723$

e-mail: sylwia@tetra.pl

Submitted: 10.01 .2017

Accepted: $\quad$ 23.02.2017 